\title{
RESPONSE SHIFT IN PATIENTS WITH LUMBAR SPINE SURGERY ASSOCIATED WITH PAINFUL LOWER LIMB LESIONS
}

\author{
Hosni H. Salama, MD. \\ Neurosurgery Departement, Zagazig University, Zagazig, Egypt
}

\begin{abstract}
Background data: Response shift is a new concept in the evaluation of patient satisfaction, application of such concept in the field of spinal surgery is important because of variation of outcome measures. Spine problems constitute a major health burden all over the world.

Purpose: Is to evaluate patient satisfaction after undergoing lumbar spine surgery and comparing patients with pure lumbar spine pathology with those having painful lower limb pathology associated with the original spine lesions.

Study design: A prospective comparative study.

Patients and methods: One hundred twenty six patients having lumbar spine pathology with radicular compression causing sciatica were evaluated pre and post operatively using patient self assessment questionnaire, visual analogue score (VAS). The study was conducted at Zagazig university hospitals from May 2014 to June 2015. There was 67 patients with associated lower limb painful pathology and 59 patients without lower limb painful lesions

Results: Fifty seven out of 59 patients became better (VAS below 40). 34 changed to 32 patients with VAS from 41 to 60, 19 changed to 20 (VAS from 61 to 80) and 6 to zero (VAS from 81 to 100) in pure lumbar pathology group, while in the second group associated with painful lower limb pathology 37 (VAS 41 to 60), 19 (VAS 61 to 80), 11(VAS 81 to 100) changed to 23, 12, and 8 respectively, 0 patients changed to 24 with VAS from 21-40.

Conclusion: patients who have lower limb painful lesions in addition to the original lumbar spine pathology tends to be less satisfied with the result of surgery than those patients having pure lumbar pathology.
\end{abstract}

Key words: Response shift. Lumbar spine surgery. Degenerative spine.

Corresponding author:Hosni Hassan Salama

Assistant professor neurosurgery Zgazig university

Email; hosni10565@yahoo.com

Mob: 00201005198939

\section{INTRODUCTION}

$\mathbf{R}$ esponse shift is a psychological phenomenon leading to changes in internal standards (recalibration); change in values (reprioritization) or reconceptualization of quality of life (QOL) ${ }^{[19]}$.Despite advances in surgical techniques, spine surgery outcomes are highly variable being subjective in nature [14]

Mismatch between patient-reported outcome measures is commonly observed ${ }^{1}$.Traditional outcome measures compares pre and post treatment self evaluation questionnaires measuring change from baseline to follow up ${ }^{[19]}$.

Howard and Dailey (1979) ${ }^{[11]}$ first identified response shift bias during studying the benefits of educational training programs. Spine lesions are suitable study for response shift because no sharp biologic or radiologic markers account for treatment effect ${ }^{[5]}$.that is because reduction in pain is the only goal of treatment in most spine problems ${ }^{[4] .}$

One of the first and most commonly applied design approaches for assessing response shift has been retrospective ratings, commonly called the then-test ${ }^{[3,21]}$. Recent researchers stressed the importance of patient participation in personal health and recovery ${ }^{[8,10]}$. Recent evidences has shown improved outcomes if patient centered evaluations were used ${ }^{[16]}$ Incomplete recovery and dealing with 
a degenerative process are two major causes for the occurrence of response shift in spine surgery ${ }^{[2]}$ The presence of associated lower limb painful pathology may affect patient satisfaction after surgery, that is why we will study the effect of this variable on patient satisfaction.

\section{PATIENTS AND METHODS}

One hundred twenty six patients having lumbar spine pathology with radicular compression causing sciatica were evaluated pre and postoperatively using patient self assessment questionnaire, visual analogue scale (VAS), there was 67 patients with associated lower limb painful pathology and 59 patients without lower limb painful lesions including osteoarthritis knee or ankle, old fractures with residual pain, varicose veins, diabetic peripheral neuropathy, herpes zoster of lumbosacral distribution, or meralgia parasthetica. The study was conducted at Zagazig university hospitals from May 2014 to June 2015.

Using the then test which is the postoperative evaluation of the preoperative complaint by the patient, then compared to the preoperative evaluation by the same patient, the difference between the two evaluations is called response shift. The difference between preoperative and postoperative evaluations is called the response.

All patients were subjected to complete neurological examination including history taking, local neurological examination, lower limb examination to confirm or exclude painful lower limb pathology, and imaging studies. All patients were asked to complete the self assessment questionnaire namely visual analogue scale (VAS).

VAS score can range from $0 \%$ to $100 \%$. A sum of $0 \%$ would indicate that the patient has no pain, and $100 \%$, would indicate the worst possible pain

Regarding the original spine problems all patients were having sciatica with or without low back pain. The main pathology was lumbar disc prolapse, lumbar canal stenosis, and spondylolisthesis.

The patients were divided into two groups the first one were those patients having pure lumbar pathology without lower limb painful lesions, the other group were those patients having painful lower limb lesions in addition to the original pathology.

All patients preoperative records were saved and the patients were subjected to the suitable surgery in the form of lumbar decompression with or without fixation.

All patients were evaluated postoperatively at week 3 and 6 months after surgery. Relieve of sciatica was complete in all patients with variable degrees of radicular tingling and numbness which resolved at the second examination at 6 months. Postoperative superficial wound infection occurred in three patients, neurological deterioration in 2 patients resolved completely at 2 nd examination.

Complicated cases were excluded from the study not to affect patient satisfaction.

\section{RESULTS}

We had one hundred twenty six patients in the two groups, there was 61 males and 65 females, the age ranged from 23 to 69 years with 43 years as the mean age.

We performed 126 operations including 56 microdiscectomy, 32 laminectomy for treating lumbar canal stenosis,38 posterior lumbar interbody fusion (PLIF) .

The associated lower limb painful pathology in the second group are mentioned in table (1) VAS score of the first group; preoperative self evaluation compared to postoperative self evaluation for the preoperative complaint are illustrated in table (2).

Fifty seven out of 59 patients $(96.6 \%)$ were improved (VAS below 40), and the difference between preoperative evaluation and postoperative evaluation of the preoperative complaints is minimal.

VAS score of the second group comparing preoperative self evaluation with the postoperative self evaluation for preoperative complaint are illustrated in table (3)

Fifty one out of 67 patients $(76.1 \%)$ improved, and the difference between preoperative complaints and the postoperative evaluation for the preoperative complaints is evident. 
Table (1): Associated lower limb painful lesions.

\begin{tabular}{|l|l|}
\hline Type of LL painful pathology & Number of patients \\
\hline Osteoarthritis knee & 22 \\
\hline Varicose veins & 7 \\
\hline Diabetic peripheral neuropathy & 20 \\
\hline Herpes zoster & 3 \\
\hline Meralgia parasthetica & 5 \\
\hline Old painful fractures & 7 \\
\hline Gouty arthritis & 3 \\
\hline
\end{tabular}

Table (2): VAS score in patients not having associated lower limb pathology

\begin{tabular}{|l|l|l|l|}
\hline VAS & Preoperative & Postoperative & $\begin{array}{l}\text { Postoperative for } \\
\text { preoperative }\end{array}$ \\
\hline $0-20$ & 0 & 40 & 0 \\
\hline $21-40$ & 0 & 17 & 0 \\
\hline $41-60$ & 34 & 1 & 32 \\
\hline $61-80$ & 19 & 1 & 20 \\
\hline $81-100$ & 6 & 0 & 7 \\
\hline
\end{tabular}

Table (3): VAS score in patients having associated lower limb pathology

\begin{tabular}{|l|l|l|l|}
\hline VAS & Preoperative & Postoperative & Postoperative for preoperative \\
\hline $0-20$ & 0 & 38 & 0 \\
\hline $21-40$ & 0 & 13 & 24 \\
\hline $41-60$ & 37 & 10 & 23 \\
\hline $61-80$ & 19 & 5 & 12 \\
\hline $81-100$ & 11 & 1 & 8 \\
\hline
\end{tabular}




\section{DISCUSSION}

The words "patient" and "customer satisfaction" are now commonly used in health care contexts ${ }^{[12]}$. Lumbar spine surgical pathology is concerned mainly in painful conditions, whether it is low back pain and /or sciatica. Evaluation of patient satisfaction in these conditions is mainly subjective, so self assessment is the cornerstone in the evaluation of success or failure of such these medical conditions.

In our study the main concern was to assess whether the presence of lower limb pathology associated with the main complaint (low back pain and/ or sciatica) has an impact on the overall surgical result with the aim of properly selecting surgery or not in some patients in whom patient satisfaction is expected to be below the hoped level of the surgeon and the patient.

There are two factors, incomplete recovery and progressive degeneration, which are common in spine surgery make it likely that patients are less than satisfied and underestimate the effectiveness of an intervention $^{[2]}$.

In cases of spinal interventions, response shifts is clearly evident and relevant when the results of treatment is partial rather than complete cure ${ }^{[19]}$ and this is the case with our second group with associated lower limb pathology in which the patient satisfaction was less than the first group without lower limb pathology.

Schwartz and Finkelistein , (2009) ${ }^{[19]}$ remembered an example, "surgical treatment for spondylolisthesis may relieve the presenting leg pain but unmask back pain once the discomfort from the leg pain is eradicated. This "partial cure" may lead to unmasking, and may account for patient dissatisfaction with surgical outcome, despite the fact that the surgery was an objective"

This example may explain our results in patients with associated lower limb pathology when the disappearance of low back pain (LBP )and/or sciatica unmask the painful lower limb pathology.

Osteoarthritis knee (OA) was the commonest associated lower limb pathology being very common in Egyptian females. The association of osteoarthritis knee and lumbar spine pathology is logic because both share the same causes mainly overweight and bad positional habits.

Weight bearing joints (spine, hip, knee, ankle) are often affected by the degenerative process because mechanical forces exerted on the joints are a major cause of osteoarthritis and one of the risk factors which could be modified with respect to weight loss and activity.

Progression of OA knee is often associated with progression of the disease in other sites especially lumbar spine ${ }^{[9]}$. Those patients in our study tend to have significant response shift due to unmasking of knee pathology after relieve of the other painful lesion (sciatica).

There is significant increase in type 2 diabetes mellitus and its complications including painful diabetic peripheral neuropathy in the Arab speaking countries as these countries has the highest rates of diabetes in the world ${ }^{[1]}$.

$53.4 \%$ of diabetic females and 45.9 of diabetic males in Egypt has painful diabetic peripheral neuropathy ${ }^{[13]}$ so its association with lumber pathology is not causal relationship but it is an association relationship.

The surgical result is the main factor in continuing undergoing the operation. In painful conditions patient satisfaction is the corner stone in the evaluation of the results of surgery.

If response shift were not taken into account, a seemingly successful surgical procedure would be viewed as being unsuccessful as measured by self-report questionnaires ${ }^{[7]}$.

In later years, it has become common to use the patients' satisfaction with treatment as an outcome parameter, and some authors even suggest this to be the most important outcome measurement ${ }^{[17]}$.

Lutz et al ${ }^{[15]}$ reported that patients' with high expectations on the treatment after lumbar disc herniation surgery had a better outcome in terms of recovery time, health state after surgery, and function/symptoms 
based on self-reported questionnaires.

We think that our explanation to the second group patients that their cure will not be complete may affected their expectation from surgery so it was reflected on their satisfaction.

The Oswestry disability index ODI is a disease-specific instrument that measures the effect of spinal disorders on 10 aspects of daily activities ${ }^{[6]}$. These aspects address basic functions such as walking or climbing stairs and participation such as sex-life and social activities $^{[20]}$, we did not use it because the additional lower limb pathology my affect the patient activities, while Schwartz et al 2008 ${ }^{[18]}$ used ODI for detection of response shift in spine surgery patients without associated lower limb pathology and find it to be positive.

We used VAS score for evaluating LBP and sciatica as a separate symptoms to precisely measure the amount of change in the same symptom along the time frame of the study

\section{CONCLUSION}

patients who have lower limb painful lesions in addition to the original lumbar spine pathology tends to be less satisfied with the result of surgery than those patients having pure lumbar pathology. These results may give us an index on the choice of the patients for surgery with lowered level of expectation for improvement in those who have associated painful lower limb pathology unrelated to the original lumbar pathology.

\section{REFERENCES}

1) Alhyas L, McKay A, Balasanthiran A, Majeed A (2011) :Prevalences of overweight, obesity, hyperglycaemia, hypertension and dyslipidaemia in the Gulf: systematic review. JRSM short reports.2(7):1-16,

2) Anderson PA, Carreon LY, Glassman SD (2009): Response shift phenomenon. Does this apply to spine outcomes research?. The Spine Journal 9(12):1037-1038.

3) Barclay-Goddard R, Lix LM, Tate R, Weinberg L, Mayo NE (2009): Response shift was identified over multiple occasions with a structural equation modeling framework. Journal of Clinical Epidemiology 62(11): 1181-1188.
4) Copay AG, Martin MM, Subach BR, Carreon LY, Glassman SD, Schuler TC, et al (2010) :Assessment of spine surgery outcomes: inconsistency of change amongst outcome measurements. The Spine Journal 10(4): 291296.

5) Don AS, Carragee E (2008): A brief overview of evidence-informed management of chronic low back pain with surgery. The Spine Journal 8(1):258-265.

6) Fairbank JC, couper J, Davles JB , O'Brien JP (1980): The Oswestry low back pain disability questionaire. Physiotherapy 66(8):271-273.

7) Finkelstein JA, Razmjou H, Schwartz CE (2009): Response shift and outcome assessment in orthopedic surgery :is there is a difference between complete vs partial treatment?JClin Epidemiol 62(11):1189-1190.

8) Greene J, Hibbard JH (2012): Why does patient activation matter? An examination of the relationships between patient activation and health-related outcomes. Journal of general internal medicine 27(5): 520-526.

9) Hassett G, Hart DJ, Doyle DV, March L., Spector TD (2006): The relation between progressive osteoarthritis of the knee and longterm progression of osteoarthritis of the hand, hip, and lumbar spine. Ann rheum dis 65(5):623-628.

10) Hibbard JH, Stockard J, Mahoney ER, Tusler M (2004): Development of the Patient Activation Measure (PAM): conceptualizing and measuring activation in patients and consumers. Health services research 39(4p1):1005-1026.

11) Howard GS, Dailey PR (1979): Responseshift bias: A source of contamination of selfreport measures. Journal of Applied Psychology 64(2):144-150.

12) Hudak PL, Wright JG (2000): The characteristics of patient satisfaction measures. Spine 25(24):3167-3177.

13) Jambart $S$, Ammache $Z$, Haddad $F$, Younes A, Hassoun A, Abdalla K, et al (2011) : Prevalence of painful diabetic peripheral neuropathy among patients with diabetes mellitus in the Middle East region. Journal of International Medical Research 39(2): 366-377.

14) Junge A, Frohlich $M$, Ahrens $S$, Hasenbring M, Sandler AJ, Grob D, et al (1996): Predictors of bad and good outcome of lumbar spine surgery: a prospective clinical study with 2 years follow-up. Spine 21(9):1056-1064. 
15) Lutz GK, Butzlaff ME, Atlas SJ, Keller RB, Singer DE, Deyo RA (1999): The relation between expectations and outcomes in surgery for sciatica. $\mathrm{J}$ Gen Intern Med 14(12):740-744.

16) Michie S, Miles J, Weinman J (2003): Patient-centredness in chronic illness. what is it and does it matter?. Patient education and counseling 51(3):197-206.

17) Rönnberg K, Lind B, Zoëga B, Halldin K, Gellerstedt M, Brisby H (2007): Patients' satisfaction with provided care/information and expectations on clinical outcome after lumbar disc herniation surgery Spine 32(2): 256-261.

18) Schwartz C, Bode R, Razmajou H, Kim D, Fenkelistien J (2008): Response shift in patients following lumbar spine surgery, impact on interpretation of Oswestry Disability Index. Spine Journal 8(5):130S.

19) Schwartz CE, Finkelistein JA (2009) :Understanding inconsistencies in patient- reported outcomes after spine treatment , Response shift phenomena. The spine journal 9(12):1039-1045.

20) Skolasky RL, Riley LH, Maggard AM, Bedi S, Wegener ST (2013) :Functional recovery in lumbar spine surgery: a controlled trial of health behavior change counseling to improve outcomes. Contemporary clinical trials 36(1): 207-217.

21) Sprangers MA, Schwartz CE (1999) : Integrating response shift into health related quality of life research: a theoretical model. Social Science \& Medicine 48(11): 1507-1515. 